\title{
Jogo educacional sobre consumo de energia elétrica
}

\author{
Adriana K. Nishida, Juliana C.Braga, Arthur Monteforte, Roseli \\ F.Benassi
}

\author{
Universidade Federal do ABC \\ keiko.nishida@gmail.com; juliana.braga@ufabc.edu.br; \\ arthur.monteforte@hotmail.com; roseli.benassieufabc.edu.br
}

\begin{abstract}
The energy is present in virtually all sectors of society and its use has been intensified throughout history. To this growth, social and environmental issues can be added, such as the intensification of the greenhouse effect and global warming. So, think about strategies that can problematize this issue, making people feel part of them and reflect on their practices should be considered and may be based on proposal of critical environmental education. One way to help to ensure that individuals can experience such problematic situations is through games. This can happen, because the games contribute to the students their interactivity and "to experience" the social and environmental problems even if virtually. In addition, the games for their motivational features can help in improving the critical view of students despite the energy problems. Thus, this paper presents a proposal to use the game as practice for the so-called critical environmental education, and its development process.
\end{abstract}

Resumo. A energia está presente em praticamente todos os setores da sociedade e o seu uso tem se intensificado ao longo da história. A este crescimento podem ser somados aumentos de problemas socioambientais, tais como a intensificação do efeito estufa e do aquecimento global. Assim, pensar em estratégias que possam problematizar este assunto, fazendo com que as pessoas se sintam parte deles e reflitam sobre suas práticas devem ser consideradas e podem ser baseadas na proposta de educação ambiental crítica. Uma forma de contribuir para que os indivíduos possam vivenciar tais situações-problema é por meio de jogos. Isso pode acontecer, pois os jogos, por sua interatividade contribuem para que os alunos "vivenciem" os problemas socioambientais mesmo que de forma virtual. Desta forma, o presente trabalho apresenta um jogo como proposta de uso para práticas da denominada educação ambiental crítica, e o seu processo de desenvolvimento.

\section{Introdução}

A energia está presente em todos os setores da sociedade, sendo utilizada para as mais diversas atividades cotidianas, que garantem o bem-estar e a oferta de bens e serviços para a humanidade (HINRICHS; KLEINBACH; REIS, 2010). 
Ao longo do tempo o consumo energético se intensificou. Do homem primitivo ao homem tecnológico não foram observadas reduções neste consumo e a partir da descoberta da energia elétrica este consumo se acentuou. Segundo projeções, se nada for feito ele continuará a crescer (GOLDEMBERG; LUCON, 2010; IPCC, 2014).

Para sustentar esta demanda de energia é necessária a implantação de fontes energéticas, o que não significa apenas a melhoria na qualidade de vida das pessoas, mas pode ser interpretado como um acarretamento de problemas de ordem local, regional e global, que atingem o meio ambiente e todas as interações que nele ocorrem.

Dentre estes problemas, pode-se citar o aumento do efeito estufa e do aquecimento global, que somados a outros como chuva ácida, poluição do ar e das águas desencadeiam consequências sociais, uma vez que são potencializadores para proliferação de doenças, longos períodos de seca e enchentes.

Considerando o exposto, é importante repensar o uso que se faz de energia, o que não deve ser feito apenas por especialistas da área energética ou políticos, mas, por todos aqueles que se enxerguem como parte desta problemática. Neste sentido, é importante lembrar que parte dos problemas ambientais existentes se deve justamente ao fato das pessoas não se enxergarem como parte inerente do meio ambiente (DE WATER; POWERS, 2011; SAUVÉ, 2005).

Deste modo, pensar em formas de se criar espaços e ferramentas que possibilitam as pessoas que dialoguem sobre as questões energéticas, em diferentes perspectivas, conhecimentos e experiências, torna-se crucial.

Uma das formas de viabilizar este diálogo é por meio de práticas educacionais, das quais neste trabalho sugerem-se aquelas relacionadas à educação ambiental, que é reconhecidamente importante, sendo debatida em eventos realizados pela Organização das Nações Unidas (ONU) e a Organização das Nações Unidas para a Educação, Ciência e Cultura (UNESCO) como Conferências Mundiais do Meio Ambiente e Seminários.

Apesar de a educação ambiental ter sua importância reconhecida, faz-se necessário saber que ela pode ser tratada/praticada de diferentes formas. Este trabalho em específico irá abordar a educação ambiental apoiada pelas tecnologias de informação e comunicação com intuito de contribuir para uma educação ambiental crítica.

A educação ambiental crítica propõe que exista um diálogo envolvido por reflexões, as quais possibilitam aos indivíduos que se enxerguem como parte de um coletivo e do meio ambiente, que saibam transitar e refletir entre os diferentes saberes, das ciências biológicas às ciências sociais, da sabedoria popular à arte, da filosofia à religião (GUIMARÃES, 2004).

Para a realização de práticas educacionais sob esta perspectiva pode-se lançar mão do uso de jogos educacionais. Os jogos têm, segundo Grando (2003) possuem o potencial de estimular a aprendizagem, o senso crítico, a criatividade, a participação e uma competição "sadia", além de possibilitar o resgate do prazer em aprender.

No cenário da educação ambiental, os jogos possibilitam a oportunidade de se tratar assuntos complexos de forma mais simplificada e didática bem como de abordálos a partir de diferentes dimensões, tais como as sociais, econômicas e ecológicas 
(TAYLOR, 1991). Além disso, os jogos também possibilitam o incentivo às atitudes positivas em relação ao meio ambiente, as pessoas e proporcionam que os jogadores pensem em resolução de problemas (MARTín, 2006).

Diante da relevância da educação ambiental e do uso de jogos como potencializadores para estimular a aprendizagem e a reflexão, este trabalho tem como objetivo apresentar a criação e desenvolvimento de um jogo que pode ser utilizado para práticas educacionais, na perspectiva de educação ambiental crítica.

\section{Revisão Bibliográfica}

\subsection{Trabalhos Relacionados}

Para realizar a buscar por trabalhos relacionados, foi realizada uma revisão sistemática. Considerou-se como trabalho relacionado todos aqueles que utilizaram jogos como apoio ao ensino sobre o consumo de energia elétrica. Para essa revisão, foram consideradas as bases: ACM Digital Library, Elsevier (Science Direct) e Springer. Também foi decidido que à medida que os trabalhos fossem lidos e estes fizessem referência a outros jogos, o Google Acadêmico seria utilizado na tentativa de localizar trabalhos a respeito destes jogos. Foi encontrado um total de 265 trabalhos e selecionados apenas aqueles que respondiam duas questões de pesquisa: Q1. Existem jogos educacionais sobre o consumo de energia? e Q2. Como estes jogos foram utilizados na prática educacional? Dos 256 trabalhos encontrados, apenas 5 foram considerados, pois somente eles respondiam as duas questões de pesquisa.

A seguir são apresentadas as descrições dos jogos encontrados nos trabalhos relacionados selecionados.

O Jogo Contract (Kontrakten) (ANTVORSKOV e RASMUSSEN 2007) foi desenvolvido em conjunto pela Learning Lab Denmark (responsável pelo storyboard e interface), Fórum de Energia das Escolas da Dinamarca (especializada em educação para energia e responsável pelos aspectos pedagógicos e educacionais) e pelo Esbensen Consulting Engenieers (especializada em eficiência energética em edifícios e energia renovável). Os propósitos do jogo foram chamar a atenção dos estudantes sobre a importância do significativo potencial de economia de energia, efetuar alterações de comportamento, apresentar energias renováveis e de apoiar e complementar os currículos das disciplinas de Ciências Naturais. Trata-se de uma simulação computacional de uma escola e de seu consumo de energia e calor, na qual os estudantes formavam grupos presenciais, que representavam empresas fictícias e competiam entre si pela obtenção do contrato de implantação de sistemas de economia de energia que seriam aplicados na escola. Nesta simulação os grupos possuíam uma quantidade de dinheiro fixa, que deveria ser administrada, levando-se em consideração as melhorias pretendidas, que são refletidas na obtenção de pontos. $\mathrm{O}$ grupo com a maior pontuação era declarado o vencedor.

O jogo Ecopet (YANG; CHIEN; LIU, 2012) foi desenvolvido em Taiwan e forneceu um mecanismo de feedback para ajudar os jogadores a consumirem menos energia elétrica, oferecendo informações como o status atual de consumo de eletricidade e de economia de energia com dicas sobre o consumo e potência dos aparelhos elétricos. O sistema simulou e monitorou as variáveis ambientais das cenas onde vivia um animal 
virtual (avatar). O objetivo do jogador era fazer com que o avatar, mais especificamente um cachorro, vivesse confortavelmente, mas com economia de energia. Sendo assim, o jogador controlava os aparelhos eletrônicos dos ambientes de forma que houvesse a maior economia de energia possível, ao mesmo tempo em que o animal se sentisse confortável A escolha pelo animal se deu em virtude dos efeitos positivos da interação homem-animal de estimação. O jogo foi construído com o objetivo de que aos jogadores fossem possibilitadas estratégias para promoção de autoconsciência sobre economia de energia, permitindo que os mesmos se sentissem motivados e que a aprendizagem também fosse possibilitada.

O Jogo Enercities (DE VRIES e KNOL, 2011 é uma simulação que começa com uma pequena vila e um pequeno pedaço de terra para se construir. $\mathrm{O}$ jogador precisava equilibrar pessoas (abordagem social), planeta (abordagem ambiental) e lucro (abordagem econômica) ao abastecer a cidade energeticamente, implementando medidas de conservação de energia e emissão de $\mathrm{CO}_{2}$ e minimizar o uso de combustíveis fósseis na geração de eletricidade assim como suas aplicações na cidade. As decisões do jogador influenciavam suas pontuações sobre pessoas, planeta e lucro. Quando fazia boas decisões o jogador recebia mais espaço para expandir sua cidade e para utilizar opções extras do jogo. Além disso, os jogadores tem a possibilidade de postar suas pontuações nas redes sociais.

O Jogo Energy Battle (GEELEN et al., 2012) foi desenvolvido pela Shifft, uma empresa da Universidade de Tecnologia de Delft e é baseado em duas competições. Para realiza-las, foram instalados medidores de consumo de energia elétrica em casas de estudantes, ao final, duas delas seriam consideradas vencedoras e receberiam prêmios. Um prêmio era dado para a casa que mais economizasse energia comparando com dados de meses anteriores e o outro para quem realizasse a construção mais criativa de blocos virtuais que eram obtidos proporcionalmente à economia realizada. $\mathrm{O}$ jogo em si fornecia os dados relativos a todos os competidores assim como dicas para redução no consumo de energia elétrica.

O Jogo Makahiki (LEE et al., 2013) fazia parte de uma competição universitária chamada Copa Kukui, na qual estudantes da Universidade do Hawaii formaram grupos, sendo estes determinados pelo andar no qual era localizado o seu dormitório. A partir disso, os jogadores tinham acesso a tarefas que deveriam ser executadas por meio de uma tela digital, que foi chamada de Smart Grid, tais tarefas eram divididas em atividades, compromissos, eventos e excursões. A cada tarefa realizada os jogadores recebiam pontos, que poderiam ser obtidos por suas práticas individuais ou coletivas.

\subsection{Análise dos trabalhos relacionados}

Dentre os parâmetros analisados o primeiro deles dizia respeito ao público principal. Foi identificada uma carência de jogos destinados ao público infantil e à terceira idade, o que significa que esforços para tentar suprir estas lacunas são considerados importantes, especialmente no caso de crianças que representam as lideranças futuras de nosso planeta, o que implica em dizer que poderão se enxergar como atores do sistema energético e, portanto, potencializadores de mudanças significativas. No caso da terceira idade, os jogos poderiam ser um estímulo à percepção de que estas pessoas possuem 
capacidade de alteração da realidade. O presente trabalho pretendeu preencher essa lacuna, por propor um jogo para o público infantil.

As escalas territoriais e temporais, por sua vez, privilegiam situações locais e momentâneas e não estabelecem relações com outras dimensões territoriais e temporais. Sendo assim, a maioria dos jogos não poderia ser utilizada para o contexto brasileiro. Já o jogo proposto pode ser aplicado a diferentes contextos, inclusive o brasileiro.

Todos os jogos estavam em língua estrangeira, o que dificulta sua aplicação para jovens alunos brasileiros que não dominam uma segunda língua. $\mathrm{O}$ jogo proposto será, inicialmente, em português.

Incoerências foram observadas, chamando atenção a premiação no jogo Energy Battle, que previa o ganho de utensílios domésticos, que estimulavam o consumo. Incoerências dessa natureza foram evitadas nesse trabalho.

Dentre os jogos analisados, observou-se que nenhum deles abordava a temática do consumo de eletricidade e sua relação com os impactos ocasionados pela implantação de uma fonte de energia, de modo detalhado. O presente trabalho preenche essa lacuna.

Os elementos de análise supracitados evidenciam que os jogos possuem potencialidades para tratar o consumo de energia de diferentes formas. Eles criam cenários dos mais variados tipos, desde animais que precisam sobreviver frente ao uso eficiente de energia até grupos que simulam empresas. No entanto, a maior parte deles explora as questões energéticas de modo superficial, pois não consideram os motivos pelos quais se consome energia, não consideram e/ou não permitem ao jogador perceber e refletir sobre o que significa reduzir o consumo de energia. E mais do que isso, questões que não são abordadas nos jogos poderiam ser trabalhadas antes ou após o seu uso, conversas, questionamentos, troca de experiências e saberes são elementos importantes, mas, muitas vezes negligenciados, em razão, principalmente, de ter o jogo como único elemento da prática educacional. Sendo assim, os jogos dificilmente proporcionam as pessoas que se estas se sintam como agentes que podem mudar realidades, como pessoas que estão inseridas dentro desta problemática.

\section{Metodologia para o Desenvolvimento do Jogo}

Para o desenvolvimento do jogo proposto nesse trabalho utilizou-se a metodologia para o desenvolvimento de objetos de aprendizagem chamada Intera (Inteligência, Tecnologias Educacionais e Recursos Acessíveis). Essa metodologia foi escolhida pelos seguintes motivos: 1) um jogo, por conter linhas de código, deve ser considerado um software e a metodologia Intera fundamenta-se em processos de desenvolvimento de software; 2) o jogo desenvolvido visou contribuir para a educação e a metodologia Intera fundamenta-se também em métodos de desenvolvimento de conteúdos educacionais; 3) a equipe envolvida nesse trabalho já continha conhecimentos da metodologia Intera

A seguir, uma breve descrição de como foi o desenvolvimento do jogo, norteado pelas etapas iterativas e incrementais da metodologia adotada.

Etapa de Gestão de Projeto: O jogo foi desenvolvido por uma equipe de quatro pessoas: professora 1, que desempenhou os papeis de demandante, professora 
conteudista, designer de games e testadora. A professora 2, que desempenhou o papel de gestora de projetos. $\mathrm{O}$ estudante 1 que realizou os papeis de desenvolvedor e analista de software. A estudante 2 atuou como designer de interface. A comunicação, além de reuniões presenciais e virtuais ocorreu também por rede social (Facebook). Com o intuito de garantir a qualidade e o direcionamento das atividades, reuniões para discutir $\mathrm{o}$ andamento das atividades, dúvidas e impedimentos encontrados foram realizadas periodicamente. O processo de desenvolvimento do jogo durou quatro meses, com dedicação semanal de 20 horas de seus desenvolvedores.

Etapa de Contextualização: Nesse ponto, definiu-se o contexto pedagógico em que o jogo deveria ser inserido. O jogo foi pensado para atividades a serem realizadas em sala de aula (presencial ou a distância) com a participação de um mediador (por exemplo, um professor). Foi definido que o público do jogo seriam crianças do ensino fundamental e a principal disciplina abordada pelo jogo seria ciências. $\mathrm{O}$ objetivo pedagógico do jogo é ajudar os estudantes a perceberem de maneira interativa as alterações necessárias no meio biológico e social para a construção de uma usina hidrelétrica, que visa atender um consumo de energia elétrica crescente. Para jogar os estudantes não precisam ter domínio em informática.

Etapa de Requisitos: nesta etapa, foram definidos os requisitos funcionais, não funcionais e pedagógicos do jogo. Dentre esses requisitos, cabe citar: i) os conteúdos abordados nos jogos devem ser interdisciplinares para permitir a reutilização em diferentes contextos e fazer com que o aluno saiba relacionar as diferentes disciplinas; ii) o jogo deveria abordar à cadeia alimentar, o ciclo da água e cálculos com operações básicas; iii) o jogo deveria ser um RPG para proporcionar uma interação suficiente para fazer com que os alunos se sintam parte do problema ambiental; iv), a tecnologia de desenvolvimento deveria permitir rápido desenvolvimento, pois o prazo era curto; v) a apresentação de conteúdo pedagógico deveria ser realizada em forma de diálogos; vi) o jogo deveria possuir cores alegres para estimular o público infantil; vii) o jogo deveria possuir músicas para diferentes situações; viii) possuir os seguintes componentes de reuso: o jogo seria dividido em módulos, ter manual para o professor, ser fácil de instalar, ter uma proposta de atividade pedagógica associada a ele. As técnicas de design de games utilizados nessa etapa foram o brainstorming e a prototipação. $\mathrm{O}$ protótipo foi realizado inicialmente pela professora conteudista e contribuiu para que o desenvolvedor e a designer de interface entendessem melhor a ideia que a professora gostaria de passar.

Etapa de Arquitetura: essa etapa envolveu a análise dos requisitos que resultou em grande parte do design do jogo. As técnicas de design de games utilizadas nessa etapa foram: roteiros (scripts) contendo os diálogos dos personagens, os documentos contendo os cenários e as missões a serem realizadas, o documento de mecânica do jogo (regras e procedimentos) e a prototipação elaborada pelo design de interface no intuito de definir a estética do jogo. Para o desenvolvimento do jogo, optou-se pela ferramenta RPG Maker VX Ace Lite, o que ocorreu por duas razões principais: ser adequada a jogos do tipo RPG e possibilitar rápido desenvolvimento, uma vez que o prazo para desenvolvimento era curto. Nesta etapa, também foram definidas as tecnologias mais adequadas para ao desenvolvimento do game e os padrões a serem adotados. 
Etapa de Desenvolvimento: nesta etapa foram desenvolvidos o código do jogo, o manual do usuário e o instalador. $\mathrm{O}$ desenvolvimento foi realizado em entregas interativas e incrementais que foram evoluindo juntamente com as etapas da metodologia. Nessa etapa também foram selecionadas e inseridas no jogo as músicas que comporiam o jogo. Ainda nessa etapa, foi desenvolvida uma atividade pedagógica no qual o game pudesse ser inserido. Esse recurso poderá auxiliar na utilização do game em sala de aula.

Etapa de Testes: Essa etapa iniciou-se quando o jogo chegou ao seu estágio beta (quando está funcionalmente completo pela primeira vez). Os testes foram realizados pela professora 1 , estudante, 1 e uma pessoa que não fazia parte do projeto. Dentre os testes realizados destacam-se: os testes de funcionalidade, identificação de defeitos, confiança técnica, precisão, instalação e disponibilização. À medida que os problemas foram descobertos pela testadora, estes eram reportados para os desenvolvedores, que realizavam as correções necessárias. Também eram realizados testes de conteúdo, pois algumas vezes, o desenvolvedor inseria no jogo elementos que não estavam de acordo com o conteúdo abordado. As avaliações de interação humanocomputador não foram realizadas por necessitar de usuários finais e/ou especialistas. Isso será realizado em projetos futuros.

Etapa de Disponibilização: Nesta etapa o jogo foi disponibilizado em um provedor gratuito (http://migre.me/kunuA) juntamente com seu manual de instalação, manual do usuário e um documento de recomendações e atividades sobre o uso do jogo para o professor (http://migre.me/kunvH).

Ambiente e padrões: Esta etapa foi responsável por controlar o ambiente técnico em que o jogo foi desenvolvido, como por exemplo, a realização de backups e controle de versionamento. A etapa foi acompanhada pela gerente do projeto ao longo de todo o desenvolvimento do jogo com o intuito de garantir a qualidade do que era desenvolvido.

Etapa de Avaliação: Esta etapa refere-se à aplicação do objeto em sala de aula, com o objetivo principal de avaliar o jogo em sala de aula. Essa avaliação pedagógica, apesar de muito importante, ainda não foi realizada, pois os autores estão estabelecendo contato com escolas públicas e professores que possam se interessar pela aplicação do jogo. Estão previstas entrevistas com professores e alunos, além da aplicação de questionários. A avaliação será centrada no uso e potencialidades do material por parte dos professores e na aprendizagem dos alunos. É importante dizer que esta etapa é essencial, e não é trivial, pois além de planejamento, articulação com instituições, ela envolve experimentação com seres humanos, tendo a necessidade de passar, inclusive, por aprovação do comitê de ética das instituições envolvidas. Essa etapa deve ser considerada como novo projeto a ser descrito em outro artigo.

\section{Resultados}

O jogo desenvolvido foi denominado "O mistério de Iluminária", a personagem principal é uma menina, Electra, que não tem preocupações acerca do consumo de energia e que é levada pelo guardião de eletricidade da cidade, Energix Eletrix, para resolver desafios e relatar suas experiências para a população da cidade. 
O jogo se desenvolve em torno da construção de uma usina hidrelétrica, tendo esta fonte sido escolhida por ser a fonte mais expressiva do Brasil. Electra deverá fazer com que os habitantes reflitam sobre suas ações para que consigam trazer de volta $o$ fornecimento de energia, que foi interrompido pelo guardião (Figura 1).

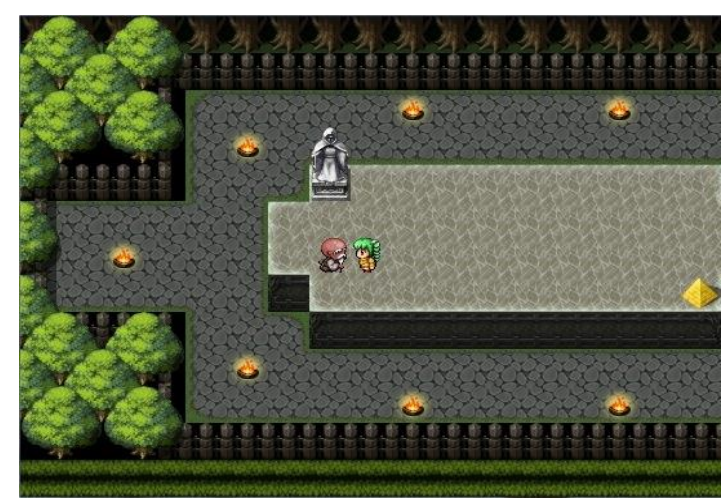

Figura 1 - Energix Eletrix e Electra.

Para resolver os desafios propostos pelo jogo, o estudante precisará lançar mão de conhecimentos de ciclo da água, cadeia alimentar, lógica para resolver puzzles e cálculos com operações básicas, mas também refletir sobre o consumo de energia e suas consequencias.

O jogo se desenvolve em três cenários distintos, que representam a fase de préimplantação da usina hidrelétrica, seu reservatório (indicando o funcionamento e a fase de pré-instalação) e a cidade onde vive Electra e o seu reencontro com os moradores, que a ajudam em um combate contra homens lâmpada incandescentes. Ao longo destes cenários a personagem se depara com pessoas que são obrigadas a deixar o local onde vivem em detrimento da construção da usina, também se deparam com as alterações necessárias no meio físico como o desflorestamento e o consequente aumento de insetos na região.

Os vídeos de apresentação do jogo podem ser encontrados em: http://migre.me/kunLb e http://migre.me/kunNh.

\section{Considerações Finais e Trabalhos Futuros}

Apesar da importância da educação ambiental, seu principal desafio é fazer com que as pessoas se sintam realmente parte dos problemas ambientais. Isso pode ser proveniente do fato das pessoas não vivenciarem as consequências que a falta de reflexão pode acarretar. Visando contribuir para que os indivíduos possam se sentir parte dos problemas ambientais, e aprimoramento da visão crítica dos estudantes a despeito dessa temática, este trabalho propôs o desenvolvimento de um jogo como subsídio para se trabalhar educação ambiental crítica. Um jogo, por ser interativo, pode auxiliar na visão crítica dos alunos e também a se sentirem parte do problema mesmo que de forma virtual.

O jogo foi desenvolvido utilizado a metodologia Intera que une processos de desenvolvimento de softwares e metodologias para a elaboração de conteúdos educacionais. A adoção da referida metodologia possibilitou a segurança necessária à 
equipe, garantindo também a confiabilidade no material produzido, graças, sobretudo, a possibilidade de ir e voltar as suas diferentes etapas. Além disso, a metodologia não deixou que a equipe fugisse do principal objetivo do jogo que é a educação e não somente o entretenimento.

Além dos conhecimentos em educação ambiental, espera-se que o jogo possa ajudar os alunos a refletirem sobre os impactos ocasionados pela construção e funcionamento de uma fonte de energia necessária para atender a sua crescente demanda, que embora retratada num mundo fictício reflete, ludicamente, o que acontece no mundo real.

É importante ressaltar que o uso do jogo sozinho não será capaz de instigar a reflexão pretendida (uso de energia elétrica). Portanto, ele deve ser utilizado como parte de uma atividade pedagógica capaz de discutir o conteúdo teórico que o envolve.

Em suma, este trabalho deixa como contribuições:

- Uma síntese dos jogos já existentes que tratam do consumo de energia. Esses jogos podem ser utilizados por professores e/ou pesquisadores no ensino de energia.

- Um jogo que pode ser utilizado por educadores com foco na educação ambiental crítica, dentro do contex to brasileiro e voltado para o público infantil.

- Reflete sobre utilização de jogos em práticas educacionais. Estes não devem ser utilizados apenas como forma de diversão e passatempo, sua utilização deve ter objetivos claros.

A continuidade deste trabalho prevê, dentre outros aspectos, sua aplicação e avaliação por parte de professores e estudantes e migração do jogo para uso em dispositivos móveis.

\section{Agradecimentos}

Os pesquisadores agradecem o apoio financeiro da UAB-UFABC/CAPES para o desenvolvimento do jogo.

\section{Referêcias}

Antvorskov, S. Rasmussen, H. F. (2007) "The Contract: An Educational Computer Game Analysing and Optimising Renewable Energy and Energy Efficiency in Schools" In: ISES WORLD CONGRESS, Berlin. Proceedings... Beijing:Tsinghua University Press, 2009. p. 3035-3039.

Braga, J. C.; Pimentel E.; Dotta, S. (2013) "Metodologia INTERA para o desenvolvimento de Objetos de Aprendizagem". In Anais do Simpósio Brasileiro de Informática na Educação.

De Vries, P. W.; Knol, E. (2001) "Serious gaming as a means to change adolescents'attitudes towards saving energy: preliminary results from the EnerCities case". In: European Distance and E-learning Network, Dublin. Proceedings... Budapeste Eden (2011). 
Geelen, D.; Kevson, D.; Boess, S.; Brezet, H. (2012) "Exploring the use of a game to stimulate energy saving in households". In: Journal of Design Research, v. 10, n. 1, p. 102-120.

Goldemberg, J.; Lucon, O. (2008) "Energia, meio ambiente e desenvolvimento". São Paulo: EdUSP.

Grando, R. C. (2001) “O jogo na educação: aspectos didático-metodológicos do jogo na educação matemática”. Unicamp. www.cempem.fae.unicamp.br/lapemmec/cursos/el654/2001/jessica_e_paula/JOGO.doc , Janeiro 2014.

Guimarães, M. "Educação Ambiental Critica". (2004) In Layrargues, P.P. (Org.). Identidades da Educação Ambiental Brasileira. Brasília: MMA/DEA.

Hinrichs, R.A.; Kleinbach, M.; Reis, L.B. (2010) "Energia e meio ambiente”. São Paulo: Câmara Brasileira de Livro.

IPCC. Energy Suply. 2007. Disponível em https://www.ipcc.ch/pdf/assessmentreport/ar4/wg3/ar4-wg3-chapter4.pdf , Abril, 2014.

DeWaters, J.; Powers, S. (2008) "Energy literacy among middle and high school youth". In Frontiers in Education Conference, 38., Saratoga Spring. Proceedings... Saratoga Spring:IEEE. http://128.153.5.187/highschool/k12/pdf/FIE08_EnergyLiteracy.pdf novembro 2013.

Lee, G. E.; Xu, Y.; Brewer, R. S.; Johnson, P. M. (2012) "Makahiki: An open source game engine for energy education and conservation". Department of Information and Computer Sciences, University of Hawaii, Honolulu, Hawaii, v. 96822, p. 11-07, https://csdl-techreports.googlecode.com/svn/trunk/techreports/2011/11-07/11-07.pdf> Novembro 2013.

Martín, R. A. del. (2006) "Juegos ambientales de gran espacio. 10 años de una experiência canária compartilhada”. Centro Nacional de Educación Ambiental, Espanha. http://www.magrama.gob.es/es/ceneam/articulos-de-opinion/2006_11azuchuae_tcm753040.pdf, Dezembro 2013.

Sauvé, L. (2005) "Educação Ambiental: possibilidades e limitações". Educação e Pesquisa, v. 31, n. 2, p. 317-322.

Taylor, J. (1991) "Guía sobre Simulación y Juegos para La Educación Ambiental”. Santiago:

OREAL;

UNESCO. http://unesdoc.unesco.org/images/0005/000569/056905so.pdf, Fevereiro 2014.

Yang, J.C.; Chien, K. H.; Liu, T.C. (2012) “A Digital Game-Based Learning System for Energy Education: An Energy Conservation PET". Turkish Online Journal of Educational Technology, v. 11, n. 2. 